\title{
Pacific and Indian Ocean climate signals in a tree-ring record of Java monsoon drought
}

\author{
Rosanne D'Arrigo, ${ }^{\mathrm{a} *}$ Rob Allan, ${ }^{\mathrm{b}}$ Rob Wilson, ${ }^{\mathrm{c}}$ Jonathan Palmer, ${ }^{\mathrm{d}}$ John Sakulich, ${ }^{\mathrm{g}}$ \\ Jason E. Smerdon, ${ }^{a}$ Satria Bijaksana ${ }^{\mathrm{e}}$ and La Ode Ngkoimani ${ }^{\mathrm{f}}$ \\ a Lamont-Doherty Earth Observatory, Palisades, NY, USA \\ ${ }^{\mathrm{b}}$ Hadley Centre for Climate Change, UK Met Office, Exeter, United Kingdom, UK \\ ${ }^{c}$ University of St. Andrews, St. Andrews, UK \\ ${ }^{\mathrm{d}}$ Gondwana Tree-Ring Laboratory, PO Box 14, Little River, Canterbury 7546, New Zealand \\ ${ }^{\mathrm{e}}$ Bandung Technical University, Bandung, Indonesia \\ f Jurusan Fisika FMIPA, Universitas Haluoleo, Sulawesi, Indonesia \\ ${ }^{\mathrm{g}}$ University of Tennessee, Knoxville, Tennessee
}

\begin{abstract}
Extreme climate conditions have dramatic socio-economic impacts on human populations across the tropics. In Indonesia, severe drought and floods have been associated with El Niño-Southern Oscillation (ENSO) events that originate in the tropical Indo-Pacific region. Recently, an Indian Ocean dipole mode (IOD) in sea surface temperature (SST) has been proposed as another potential cause of drought and flood extremes in western Indonesia and elsewhere around the Indian Ocean rim. The nature of such variability and its degree of independence from the ENSO system are topics of recent debate, but understanding is hampered by the scarcity of long instrumental records for the tropics. Here, we describe a tree-ring reconstruction of the Palmer Drought Severity Index (PDSI) for Java, Indonesia, that preserves a history of ENSO and IOD-related extremes over the past 217 years. Extreme Javan droughts correspond well to known ENSO and IOD events in recent decades, and most extreme droughts before this recent period can be explained by known ENSO episodes. Coral proxies from regions near or within the two poles of the IOD show good agreement with Javan PDSI extremes over the past $\sim 150$ years. The El Niño of 1877, in conjunction with a positive IOD, was one of the most intense and widespread episodes of the past two centuries, based on instrumental and proxy data from across the tropical Indo-Pacific and Asian monsoon regions. Although Java droughts typically show the expected association with El Niño-like conditions and failed Indian monsoons, others (mainly linked to positive IOD conditions) co-occur with a strengthened Indian monsoon, suggesting linkages between the Indian monsoon, Indonesian drought and Indian Ocean climatic variability. The close associations between the Java PDSI, ENSO and Indian Ocean climate are consistent with the hypothesis that interannual ENSO to decadal ENSO-like modes interact to generate dipole-like Indian Ocean variability. Copyright (C) 2008 Royal Meteorological Society
\end{abstract}

KEY WORDS Indian Ocean; tree rings; PDSI; drought; monsoon; dipole; ENSO; Indonesia

Received 4 June 2007; Revised 6 December 2007; Accepted 8 December 2007

\section{Introduction}

The core physical ocean-atmosphere interactions underlying the El Niño-Southern Oscillation (ENSO) phenomenon are centered on the Indo-Pacific region, but its climatic impacts can be of global extent (Allan et al., 2003). The dominant influence of ENSO on the Indian Ocean does not preclude, however, the possible existence of more independent modes of Indian Ocean variability. It has been proposed that an Indian Ocean dipole mode (IOD) exists that is largely distinct from ENSO and contributes significantly to climate around the Indian Ocean rim (Saji et al., 1999; Webster et al., 1999; Behera et al., 2006) and the globe (Saji and Yamagata, 2003). The Dipole Mode Index (DMI) is defined

* Correspondence to: Rosanne D'Arrigo, Tree-Ring Laboratory, Lamont-Doherty Earth Observatory, 61 Route 9W, Palisades, NY 10964, USA. E-mail: rdd@ldeo.columbia.edu as the sea surface temperature (SST) difference between the western $\left(50^{\circ}-70^{\circ} \mathrm{E}, 10^{\circ} \mathrm{S}-10^{\circ} \mathrm{N}\right.$, off Kenya) and eastern $\left(90^{\circ}-110^{\circ} \mathrm{E}, 0^{\circ}-10^{\circ} \mathrm{S}\right.$, off Java/Sumatra) Indian Ocean. During what have been described as positive IOD events, a cold SST anomaly forms in the eastern Indian Ocean during the boreal summer and fall, contributing to drought conditions over western Indonesia. These cold SSTs are linked, via various positive feedbacks, to intensified southeasterly trade winds, shallowing of the thermocline and other physical changes in the eastern Indian Ocean (Saji et al., 1999). Meanwhile, warm SST anomalies occur in the western Indian Ocean, intensifying rainfall in eastern Africa. Opposite patterns are typically observed during negative IODs, although anomalies are not typically as strong as those during the positive IOD mode. Over Java/Sumatra, positive (negative) IODs tend to result in intense drought (wet) extremes, with anomalies of the same sign as those 
that occur during El Niño (La Niña) episodes. Equatorial Indian Ocean zonal wind anomalies (EQWIN) are another closely related atmospheric component of Indian Ocean variability linked to the IOD and the Indian monsoon (Gadgil et al., 2004; Ihara et al., 2007), and are closely linked to ENSO variability (Wright et al., 1985).

Other researchers have argued that the IOD in its evolution, frequency spectrum, SST pattern and proposed near-global influence is simply another phase of the ocean-atmosphere interactions underlying IndoPacific ENSO variability, that results from the interaction of quasi-biennial, 'classical' ENSO and quasi-decadal ENSO-like signals in SST and sea level pressure (SLP) (Allan et al., 2001; Baquero-Bernal et al., 2002; Dommenget and Latif, 2002; Allan et al., 2003). These modes can combine and interact to produce protracted ENSO conditions, with negative or positive phasing, over the Indian Ocean sector (Allan and D'Arrigo, 1999; Allan, 2000; Allan et al., 2003). Allan et al. (2003) have indicated that the bulk of IOD events of either sign occur in conjunction with some type of El Niño or La Niña event or episode. In this view, there are a range of different types of ENSO events and episodes which can be strong to weak in magnitude, short to 'protracted' in temporal extent, or even of abortive nature. Additionally, Allan et al. $(2001,2003)$ stress that the interpretation of Indian Ocean domain-only empirical orthogonal function (EOF) analysis in IOD studies fails to recognize that, though orthogonal at zero lag, the first two EOF modes are confounded and have considerable shared variance, being significantly correlated at leads and lags of around nine months. Thus, the second EOF mode (the IOD) is simply representative of another phase of the first EOF mode (ENSO). Similar restricted domain EOF and singular value decomposition (SVD) analyses in the Pacific Ocean by Trenberth and Stepaniak (2001) and Kumar et al. (2006) have encountered a similar situation to the Indian Ocean, but report that their first and second EOF/SVD modes are simply different 'flavours' of the ENSO response in that ocean basin. Alternatively, ENSO may be only one of several potential triggers for dipoletype conditions in the Indian Ocean (Fischer et al., 2005).

A better understanding of the complex interactions between ENSO and Indian Ocean climate requires longer time series for analysis than those presently available from instrumental data. High-resolution tropical proxy records, mainly derived from tree rings, corals and ice cores, yield valuable information on past climate, but such records are relatively rare for the Indian Ocean and surrounding land areas. Among such proxies, coral records of SST for the western Indian Ocean (Figure 1) have been published for Malindi, Kenya (Cole et al., 2000; Kayanne et al., 2006) and for the Seychelles (Charles et al., 1997; Pfeiffer and Dullo, 2006). Both sites lie within or near the western pole of the IOD and have been used in these studies to demonstrate annual to decadal-scale impacts of ENSO on Indian Ocean climate. A combined Seychelles coral record (Charles et al., 1997; Pfeiffer and Dullo, 2006) produced seasonal correlations

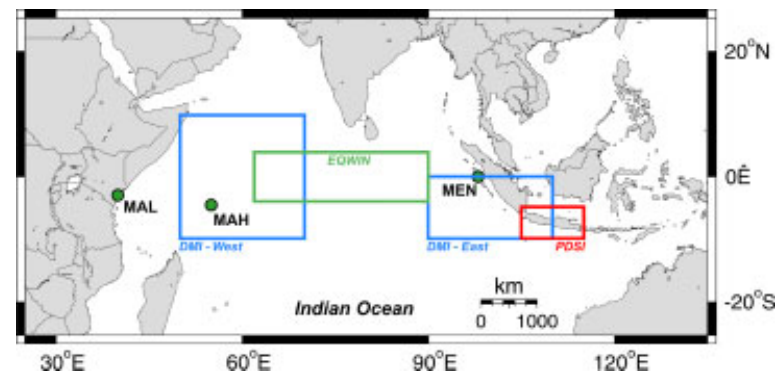

Figure 1. Map showing location of gridcell (in red) used to develop Java PDSI reconstruction (D'Arrigo et al., 2006a) and the two gridcells of SST (blue boxes) used to define the DMI (Saji et al., 1999). Note overlap of Java PDSI gridcell with that of the eastern pole of the IOD. Also indicated in green is the gridcell used to develop the EQWIN index of equatorial zonal winds for the central Indian Ocean (Gadgil et al., 2004; Ihara et al., 2007). Also shown are locations of coral proxies mentioned in the text - in the western Indian Ocean, for the Seychelles (Charles et al., 1997) and Malindi (Cole et al., 2000); in the eastern Indian Ocean, for the Mentawai Islands (Abram et al., 2003). This figure is available in colour online at www.interscience.wiley.com/ijoc

with ENSO that were basically stationary over time, with cross-spectral analyses indicating coherency between the coral index and ENSO, supporting the concept that decadal ENSO variability influences the Indian Ocean. Elsewhere in the Indian Ocean, coral series exist for sites near Madagascar (Zinke et al., 2004, 2005), the Chagos Archipelago (Pfeiffer et al., 2004) and other locations (Chakraborty, 2006). Of these published Indian Ocean coral records, only one extends back further than $\sim 150$ years (for the Ifaty site off southwestern Madagascar; 1659-1995). A tree-ring chronology for Zimbabwe, one of the few land-based high-resolution records for the western Indian Ocean rim, begins in the late 18th century and indicates drought and wet extremes that correlate well, although intermittently, with ENSO (Therrell et al., 2006).

The eastern Indian Ocean, just west of the islands of Java and Sumatra, is considered to be the more robust of the two poles of IOD variability and is also where such events tend to originate (Saji and Yamagata, 2003; Meyers et al., 2007). From within the actual region of peak SST anomaly off Java/Sumatra used to define the IOD, coral $\delta^{18} \mathrm{O}$ and $\mathrm{Sr} / \mathrm{Ca}$ records for the Mentawai Islands (Figure 1) reveal cold and dry SST anomalies in response to positive IODs (Abram et al., 2003, 2005, 2007). Mentawai fossil corals were used to suggest that the magnitude of the very strong 1997-1998 IOD (also a severe ENSO) was not unique relative to events earlier in the Holocene (Abram et al., 2003, 2007). Abram et al. (2003; pers. comm. 2006) argue that the cold SSTs off Sumatra during positive IODs distinguish such events from the Indian Ocean basin-wide warming signal during El Niños. On the other hand, Baquero-Bernal et al. (2002) point out that El Niños can also help force dipoletype structure and cold SSTs in the eastern Indian Ocean. Charles et al. (2003) used a network of Indian Ocean coral records to investigate ENSO and the IOD, finding that their zonal isotopic gradient was significantly 
correlated with central Pacific SSTs, and that this coral dipole resulted from strong ENSO-like teleconnections in the Indian Ocean, as opposed to being the result of unique Indian Ocean or monsoonal dynamics. More importantly, Allan et al. (2001, 2003) and Reason et al. (2000) have shown that the austral spring Indian Ocean SST pattern of the IOD is identical to that of ENSO events in that season and ocean basin, and that the basin-wide SST response across the Indian Ocean reported above is only seen at the peak ENSO phase in the austral summer.

Here we use a tree-ring-based reconstruction of the boreal fall (Oct-Nov) Palmer Drought Severity Index (PDSI) for Java, Indonesia (D'Arrigo et al., 2006a) to investigate drought and wetness extremes, and their relation to Indian Ocean and ENSO variability over the past two centuries. Positive (negative) PDSI indicates wet (dry) conditions. Because Indonesia is uniquely situated between the Pacific and Indian Oceans, its rainfall is impacted by SST variability in both basins (Aldrian and Susanto, 2003). Java, along with the island of Sumatra and the adjacent smaller islands, experiences the greatest Indian Ocean-related climate impacts in all of Indonesia (Saji and Yamagata, 2003). Indonesian treering and coral records were used previously to reconstruct western Pacific warm pool SSTs in relation to ENSO (D'Arrigo et al., 2006b). We demonstrate that the Java PDSI reconstruction, derived from a land area that overlaps the eastern pole of the IOD (Figure 1), also captures features of Indian Ocean climate. At 217 years in length, it is one of the longest continuous, highresolution records available for investigating rainfall variability in the tropical Indo-Pacific. We also compare the PDSI reconstruction to other high-resolution proxies from the Indian Ocean to assess spatial variations in IOD and ENSO-related impacts over the past two centuries. The conceptual framework of the paper is, therefore, to assess the interrelationships between ENSO, the IOD, and the Indian monsoon, using both instrumental and highresolution proxy climate records for the tropical IndoPacific region.

\section{Data and methods}

\subsection{Instrumental data:}

We use the monthly DMI of Saji et al. (1999; http://www. jamstec.go.jp/frsgc/research/d1/iod/), defined in the Introduction, which begins in 1958. The two SST boxes used to define the DMI are indicated in Figure 1. Decadal periodicities (longer than 7 years) were removed by Saji et al. (1999) in calculating their index. We also use the global SST dataset of Kaplan et al. (1998), as well as an extended DMI (1869-2002) based on these data (from the IOD website cited above). The extended record, however, includes early periods of relatively sparse data coverage (with possibly spurious values) for which data was interpolated (Kaplan et al., 1998). For comparison, a version of the DMI was also created from the HADSST2 dataset (Rayner et al., 2006). A monthly index of zonal surface wind anomalies for EQWIN is used from ICOADS data for averaged anomalies over $62^{\circ}-90^{\circ} \mathrm{E}$, $4^{\circ} \mathrm{N}-4^{\circ} \mathrm{S}$, for $1881-1997$ (Worley et al., 2005). Rainfall data were obtained from the Global Precipitation Climatology Centre (GPCC) Variability Analysis of Surface Climate Observations (version Vasclim-0 0.5, Beck et al., 2005) precipitation dataset from 1951 to 2000. Also used in this study are standard ENSO indices (http://www.cpc.noaa.gov), including Niño-3.4 SSTs; the Jakarta rain days record (Konnen et al., 1998), the allIndia monsoon index (http://www.tropmet.res.in/) and the Indian monsoon index of Sontakke et al. (1993), Sontakke and Singh (1996). An index of the Southern Oscillation (SOI) was developed from the gridcells representing Tahiti and Darwin from the HADSLP2 dataset (Allan and Ansell, 2006).

\subsection{Proxy data}

The boreal fall PDSI reconstruction, described in detail in D'Arrigo et al. (2006a), spans the interval from 1787 to 2003 (instrumental values were spliced onto the PDSI reconstruction after 1988 following adjustment for mean and variance). The PDSI incorporates parameters of both rainfall and temperature and is a proxy for soil moisture and streamflow (Dai et al., 2004; see D'Arrigo et al., 2006a for further details). Based on nine Javan treering records of teak (Tectona grandis) and one coral series, the reconstruction is reasonably well validated and is used herein to evaluate Indian Ocean-related PDSI variability for the eastern pole of the IOD (Figure 1), complementing the eastern Indian Ocean coral data (Abram et al., 2003, time series not available). This Java reconstruction is most sensitive to adverse climatic events such as drought (rather than more favorable wetter conditions), as has been found for other treering series (Fritts, 1976). For the western Indian Ocean, we compare the PDSI reconstruction to the Seychelles coral $\delta^{18} \mathrm{O}$ record (Charles et al., 1997; 1846-1994; detrended for the boreal fall season), which is available at monthly resolution, unlike the Malindi, Kenya series. Note, however, that the Seychelles and Mentawai records date back only a few decades prior to the extended DMI. We also evaluate the proxy data in relation to other Indian Ocean, Indian monsoon and ENSO-related indices (Table I, Figure 1). See Table II for a listing of acronyms and data used in this study. Instrumental databased listings of IODs and ENSO events in Saji and Yamagata (2003), and the consensus ENSO listings of two sources:

1. J. Null (2004; http://ggweather.com/enso/years.htm); El Niño and La Niña Years: A consensus listing, using events that appear on $3 / 4$ of the following 4 widely used lists: Western Region Climate Center, Climate Diagnostics Center, Climate Prediction Center, Multivariate ENSO Index from Climate Diagnostics Center; and

2. D. O'Sullivan (1994): http://www.longpaddock.qld.gov. au/Help/ElNinoSouthernOscillation/ 
Table I. Correlation matrices of Java PDSI reconstruction, instrumental indices of IOD and ENSO, and other records for tropical Indo-Pacific for September-October season. Matrix A is for common 1958-1994 period. $90 \%=>0.27$ and $95 \%=>0.32$; matrix B for full period of common overlap between each series. Significance values and degrees of freedom

(a)

(N) shown; shaded correlations not significant at these levels.

KAP DMI SAJI DMI HAD DMI EQWIN SST EAST SST WEST NINO3 SOI JAK SEY ALL IND SINGH

\begin{tabular}{|c|c|c|c|c|c|c|c|c|c|c|c|c|}
\hline PDSI & -0.64 & -0.59 & -0.59 & 0.73 & 0.56 & -0.56 & -0.53 & 0.58 & 0.70 & 0.62 & 0.30 & 0.09 \\
\hline KAP DMI & & 0.91 & 0.92 & -0.87 & -0.89 & 0.85 & 0.59 & -0.65 & $-0.64-$ & -0.44 & -0.19 & -0.14 \\
\hline SAJI DMI & & & 0.92 & -0.83 & -0.81 & 0.78 & 0.50 & -0.58 & -0.59 & -0.42 & -0.21 & -0.14 \\
\hline HAD DMI & & & & -0.87 & -0.87 & 0.72 & 0.43 & -0.49 & -0.60 & -0.46 & -0.14 & -0.04 \\
\hline EQWIN & & & & & 0.85 & -0.66 & -0.42 & 0.48 & 0.67 & 0.41 & 0.10 & -0.04 \\
\hline EAST & & & & & & -0.52 & -0.40 & 0.47 & 0.48 & 0.19 & 0.17 & -0.04 \\
\hline WEST & & & & & & & 0.65 & -0.68 & -0.66 & -0.60 & -0.17 & -0.29 \\
\hline NINO3 & & & & & & & & -0.87 & -0.47 & -0.42 & -0.59 & -0.64 \\
\hline SOI & & & & & & & & & 0.49 & 0.40 & 0.51 & 0.45 \\
\hline JAK & & & & & & & & & & 0.47 & 0.05 & 0.06 \\
\hline SEY & & & & & & & & & & & 0.38 & 0.25 \\
\hline ALL IND & & & & & & & & & & & & 0.66 \\
\hline
\end{tabular}

(b)

\begin{tabular}{|c|c|c|c|c|c|c|c|c|c|c|c|c|}
\hline & KAP DMI & SAJI DMI & HAD DMI & EQWIN & SST EAST & SST WEST & NINO3 & SOI & JAK & SEY & ALL IND & SINGH \\
\hline PDSI & -0.45 & -0.59 & -0.39 & 0.51 & 0.29 & -0.36 & -0.39 & 0.39 & 0.54 & 0.40 & 0.25 & 0.23 \\
\hline $\mathrm{p}$ & 0.00 & 0.00 & 0.00 & 0.00 & 0.00 & 0.00 & 0.00 & 0.00 & 0.00 & 0.00 & 0.00 & 0.01 \\
\hline $\mathrm{N}$ & 134 & 42 & 123 & 103 & 147 & 147 & 148 & 148 & 126 & 149 & 129 & 140 \\
\hline Kap DMI & & 0.92 & 0.90 & -0.73 & -0.77 & 0.80 & 0.61 & -0.61 & -0.65 & -0.37 & -0.25 & -0.30 \\
\hline $\mathrm{p}$ & & 0.00 & 0.00 & 0.00 & 0.00 & 0.00 & 0.00 & 0.00 & 0.00 & 0.00 & 0.00 & 0.00 \\
\hline $\mathrm{N}$ & & 42 & 122 & 103 & 134 & 134 & 134 & 134 & 121 & 126 & 129 & 127 \\
\hline Saji DMI & & & 0.91 & -0.85 & -0.85 & 0.77 & 0.56 & -0.64 & -0.65 & -0.42 & -0.19 & -0.13 \\
\hline $\mathrm{p}$ & & & 0.00 & 0.00 & 0.00 & 0.00 & 0.00 & 0.00 & 0.00 & 0.01 & 0.23 & 0.44 \\
\hline $\mathrm{N}$ & & & 42 & 40 & 42 & 42 & 42 & 42 & 40 & 37 & 42 & 38 \\
\hline HAD DMI & & & & -0.70 & -0.67 & 0.78 & 0.54 & -0.54 & -0.62 & -0.38 & -0.22 & -0.23 \\
\hline $\mathrm{p}$ & & & & 0.00 & 0.00 & 0.00 & 0.00 & 0.00 & 0.00 & 0.00 & 0.02 & 0.01 \\
\hline $\mathrm{N}$ & & & & 103 & 122 & 122 & 126 & 126 & 109 & 114 & 119 & 115 \\
\hline EQUIN & & & & & 0.62 & -0.58 & -0.48 & 0.59 & 0.64 & 0.31 & 0.05 & 0.04 \\
\hline $\mathrm{p}$ & & & & & 0.00 & 0.00 & 0.00 & 0.00 & 0.00 & 0.00 & 0.58 & 0.70 \\
\hline $\mathrm{N}$ & & & & & 103 & 103 & 103 & 103 & 95 & 100 & 103 & 101 \\
\hline East & & & & & & -0.14 & -0.34 & 0.41 & 0.40 & 0.11 & 0.20 & 0.15 \\
\hline $\mathrm{p}$ & & & & & & 0.09 & 0.00 & 0.00 & 0.00 & 0.22 & 0.02 & 0.08 \\
\hline $\mathrm{N}$ & & & & & & 147 & 147 & 147 & 126 & 139 & 129 & 140 \\
\hline West & & & & & & & 0.55 & -0.50 & -0.61 & -0.42 & -0.20 & -0.28 \\
\hline $\mathrm{p}$ & & & & & & & 0.00 & 0.00 & 0.00 & 0.00 & 0.02 & 0.00 \\
\hline $\mathrm{N}$ & & & & & & & 147 & 147 & 126 & 139 & 129 & 140 \\
\hline NINO3 & & & & & & & & -0.74 & -0.53 & -0.40 & -0.51 & -0.65 \\
\hline $\mathrm{p}$ & & & & & & & & 0.00 & 0.00 & 0.00 & 0.00 & 0.00 \\
\hline $\mathrm{N}$ & & & & & & & & 151 & 126 & 139 & 129 & 140 \\
\hline SOI & & & & & & & & & 0.56 & 0.30 & 0.44 & 0.46 \\
\hline $\mathrm{p}$ & & & & & & & & & 0.00 & 0.00 & 0.00 & 0.00 \\
\hline $\mathrm{N}$ & & & & & & & & & 126 & 139 & 129 & 140 \\
\hline Jak & & & & & & & & & & 0.41 & 0.15 & 0.24 \\
\hline $\mathrm{p}$ & & & & & & & & & & 0.00 & 0.11 & 0.01 \\
\hline $\mathrm{N}$ & & & & & & & & & & 123 & 119 & 124 \\
\hline SEY & & & & & & & & & & & 0.14 & 0.17 \\
\hline $\mathrm{p}$ & & & & & & & & & & & 0.13 & 0.04 \\
\hline $\mathrm{N}$ & & & & & & & & & & & 124 & 139 \\
\hline All Ind & & & & & & & & & & & & 0.62 \\
\hline $\mathrm{p}$ & & & & & & & & & & & & 0.00 \\
\hline $\mathrm{N}$ & & & & & & & & & & & & 125 \\
\hline
\end{tabular}


Table II. Listing of acronyms and data sets used in this study. Refer to reference list and text for complete citations and definitions.

\begin{tabular}{ll}
\hline Indices and datasets & \multicolumn{1}{c}{ References } \\
\hline Saji DMI & Saji et al. (1999) \\
Kaplan DMI & Kaplan et al. (1998) \\
Hadley DMI & Rayner et al. (2006) \\
EQWIN index (COADS) & Worley et al. (2005) \\
East Dipole Box & Kaplan et al. (1998) \\
West Dipole Box & Kaplan et al. (1998) \\
SOI & Allan and Ansell (2006) \\
All-India Monsoon Rainfall & Sontakke and Singh (1996) \\
Jakarta Rain Days & Konnen et al. (1998) \\
Instrumental PDSI & Dai et al. (2004) \\
Java tree-ring PDSI & D'Arrigo et al. (2006a) \\
Seychelles coral & Charles et al. (1997) \\
Rainfall data (Vasclim) & Beck et al. (2005) \\
Listings of IOD, ENSO events & Saji and Yamagata (2003) \\
Listings of ENSO events & Null (2004), O'Sullivan \\
& (1994) \\
Documentary, multiproxy & Ortlieb (2000), Whetton and \\
ENSO records & Rutherford (1994) \\
\hline
\end{tabular}

are used to define such events in the proxy data. ENSO events are identified as those years which are listed in both these sources (Null, 2004; O'Sullivan, 1994). Prior to the instrumental period, we identify ENSO warm event years as those which were indicated in both the Ortlieb (2000) documentary listing of ENSO warm events (updated from Quinn's earlier analysis), and in the listing of Whetton and Rutherford (1994) for the Eastern Hemisphere. Like the proxy records, these historical listings also have uncertainties due to varying resolution and spatial representation, and other considerations.

The proxy and instrumental records were evaluated using simple correlation analysis (Table I). Spatial correlation fields were computed using the Kaplan et al. (1998) SST dataset. Spectral analyses were performed using the Multi-Taper Method (MTM; Mann and Lees, 1996) and Morlet wavelet and wavelet coherency analysis (Torrence and Compo, 1998; Grinsted et al., 2004). KNMI Climate Explorer (http://climexp.knmi.nl) and MATLAB were used for some computations and figures.

\section{Results}

To test the ability of the PDSI reconstruction to provide information on past Indian Ocean climate, this record was first correlated to the IOD indices (DMI) of Saji et al. (1999; http://www.jamstec.go.jp/frsgc/research/d1/iod/) and those derived from Kaplan et al. (1998) and Rayner et al. (2006) during the latter half of the 20th century (since 1958), when the IOD indices are considered most reliable (Table I(a), Figure 2(a)). The PDSI reconstruction is most strongly correlated with the DMI $(r=-0.64$ using the Kaplan series from 1958 to 1994) for the boreal fall months (Sept-Oct) of peak IOD variability. Correlation over the full interval of Kaplan extended SST dipole data since 1869 is $r=-0.45$ (Table I(b)). Correlations between the reconstructed PDSI and SST data for the two gridcells representing the poles of the IOD are statistically significant $(p \leq 0.05)$ and of opposite sign. The negative correlation between the reconstructed PDSI and DMI is consistent with the tendency for drier conditions over western Indonesia to occur during positive IOD episodes. A significant correlation is also found with the EQWIN index ( $r=0.73, p<0.05,1958-1994$, Figure 2(b)). Statistically significant correlations are also found with the boreal fall Niño-3.4 SSTs and other indices of tropical Indo-Pacific climate (Table I). These findings indicate that the PDSI reconstruction reflects Indian Ocean as well as tropical Pacific Ocean-related climatic variability (D'Arrigo et al., 2006a,b).

Additional evidence for a relationship between the Java PDSI and Indian Ocean SSTs is presented in Figure 3, which shows spatial correlation fields between IndoPacific SSTs, the Kaplan DMI, HADSLP2 SOI and the PDSI reconstruction for the boreal fall season for both recent (post-1958) and century-long (post-1880) time series. Both the DMI and PDSI correlation patterns reveal dipole-like structure in Indian Ocean SSTs over recent decades as well as over the full length of instrumental record (Figure 3(a)-(d)). This is also the case for Niño3.4 SST (Figure 3(e) and (f)) and the SOI (Figure 3(g) and (h)). This finding is consistent with Allan et al. (2001) and Baquero-Bernal et al. (2002), both of whom observed that ENSO can also cause dipole-like patterns in the Indian Ocean. Figure 3(a)-(h) all show coincident and coherent IOD and ENSO structures in SST during the boreal autumn season that are very similar to the SST composites in Allan et al. (2003). Spatial correlation fields of the Java PDSI reconstruction with precipitation reveal the strong opposing relationship between rainfall over eastern Africa/Arabia versus Indonesia/Australia in boreal fall that relates to dipole-like SST conditions in the Indian Ocean and to ENSO (Figure 3(i)-(j)).

To further investigate the correspondence between the Javan PDSI and climate anomalies related to Indian and Pacific Ocean variability, PDSI values below and above 1 standard deviation (representing drought and wet periods) were identified over the length of the reconstruction (1787-2003). In Figure 4(a), PDSI drought years are compared to the instrumental, historical and proxy records of positive IOD and ENSO warm events (see 'Data and Methods'). Since 1787, of the 29 drought years $(>=-1$ standard deviation), $19(66 \%)$ coincide with El Niños. With the 47 ENSO warm events identified since 1787 (see Figure 4), the probability that 19 coincident years are identified by chance (i.e. relative to using random time series) is extremely low $(p<0.000)$. However, this relationship appears to break down prior to 1850 (shown by open diamonds in Figure 4(a); only $25 \%$ (1812 and $1838-p=0.28$ ) coincide). Since 1850 , of the 21 drought events (relative to 37 ENSO warm events), $17(81 \% ; p<0.0000)$ coincide with El Niños. The relationship with ENSO is not as coherent when wet events are examined. Of the 31 reconstructed wet years since 


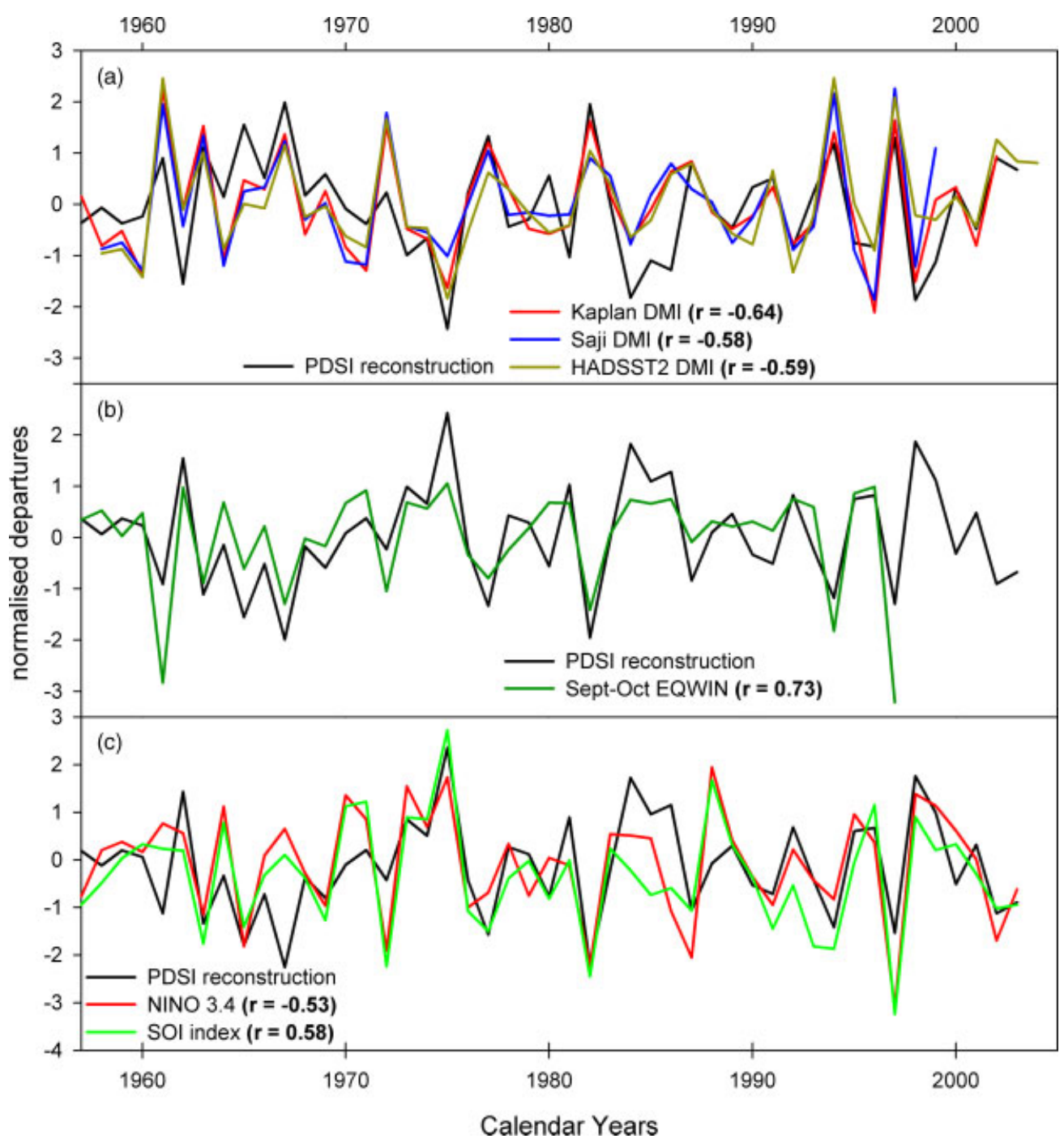

Figure 2. Comparison between Indian Ocean climate indices and Java PDSI reconstruction. (a) Java PDSI reconstruction and Sept-Oct DMIs of Saji et al. (1999), Kaplan et al. (1998) and HADSST2 (Rayner et al., 2006). Sign of PDSI reconstruction is reversed. (b) with Sept-Oct EQWIN index. All correlations (calculated over the 1958-1994 period, Table I(a)) are statistically significant above the 99\% level. Instrumental values were spliced onto the PDSI reconstruction after 1988 after adjustment for mean and variance. This figure is available in colour online at www.interscience.wiley.com/ijoc

1850 , only $7(22 \% ; p=0.15)$ coincide with La Niña events. Additionally, seven of these wet years actually coincide with El Niño events. A similar situation exists when the wet/dry years are compared to IODs since 1960, when such events appear to have increased in frequency (Saji and Yamagata, 2003). Of the nine droughts over this period, seven $(78 \% ; p<0.0000)$ coincide with positive IOD events, while only one $(17 \% p=0.40)$ of the 6 wet years coincides with a negative IOD (not shown). As noted previously, the negative IOD is also a less robust pattern than the positive IOD mode. Thus, while many of these comparisons of extreme events (and the correlations in Table I) are highly significant statistically, and together account for a sizeable proportion of the PDSI variance (e.g. as we demonstrated in R. D'Arrigo and R. Wilson (in press)), it is clear that there is additional variance not accounted for by the variables analysed herein. This fact reflects, at least in part, quality issues and varying spatial representation in the early historical records as well as the proxy records themselves, such that they are not perfect measures of the phenomena that we are examining. There are also other factors forcing climate in these regions (e.g. volcanism in the early 1800s).

Reconstructed Java droughts thus correspond reasonably well with the positive IODs and ENSO warm events identified in instrumental, historical or proxy records, reflecting their links to both tropical Indian Ocean as well as Pacific Ocean SSTs (Figure 4(a)). Before 1961, only one major positive IOD has been identified over the past few centuries (in 1877, also an El Niño; noted in the Mentawai corals - Abram et al., 2003). Variance in the early part of the extended DMI reflects this low IOD activity: for $1878-1960$ the average variance is 0.08 , versus 0.21 for 1961-2002. Ihara et al. (in press) describe different regimes in the instrumental period, related to differential warming in the Indian Ocean, in which there are different frequencies of positive and negative dipole events. Most droughts can be explained by ENSO events 
(a)

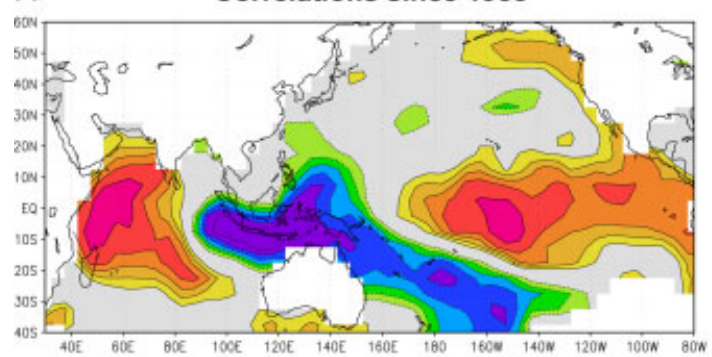

(c)

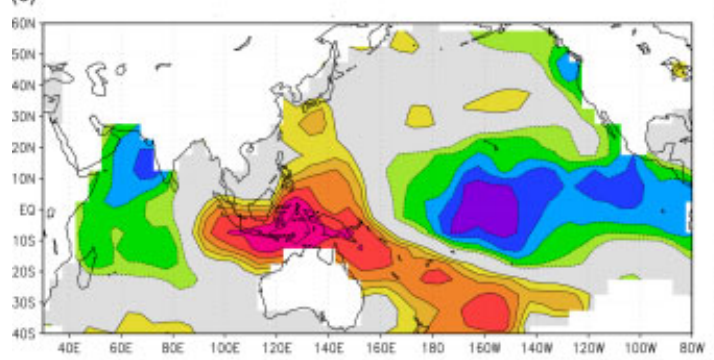

(e)
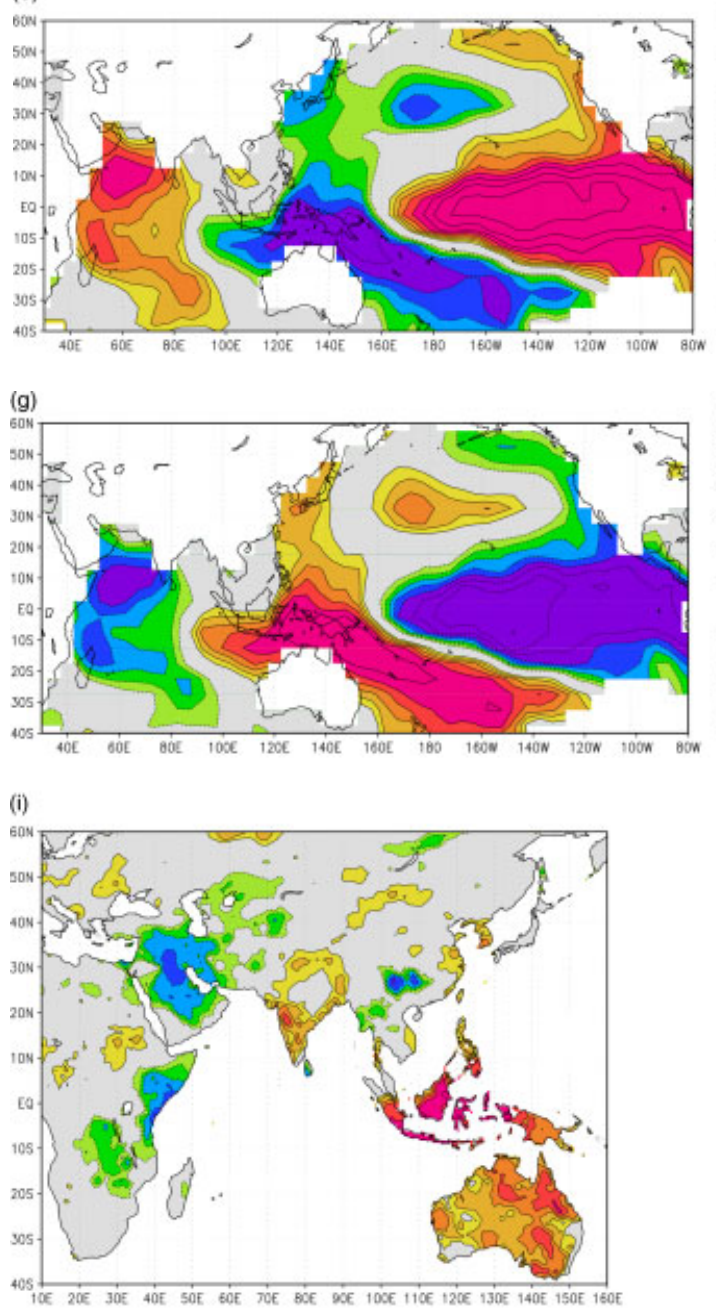

(b) Correlations since 19th Century

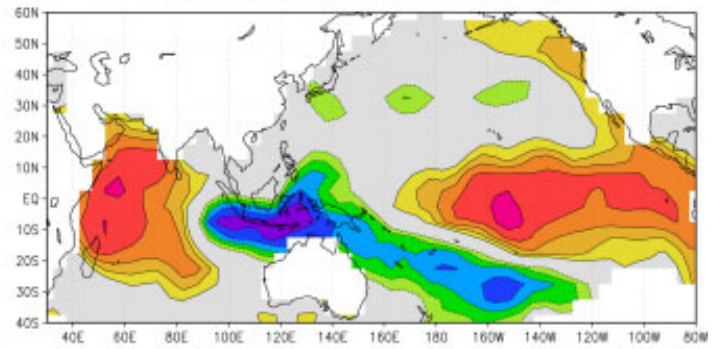

(d)
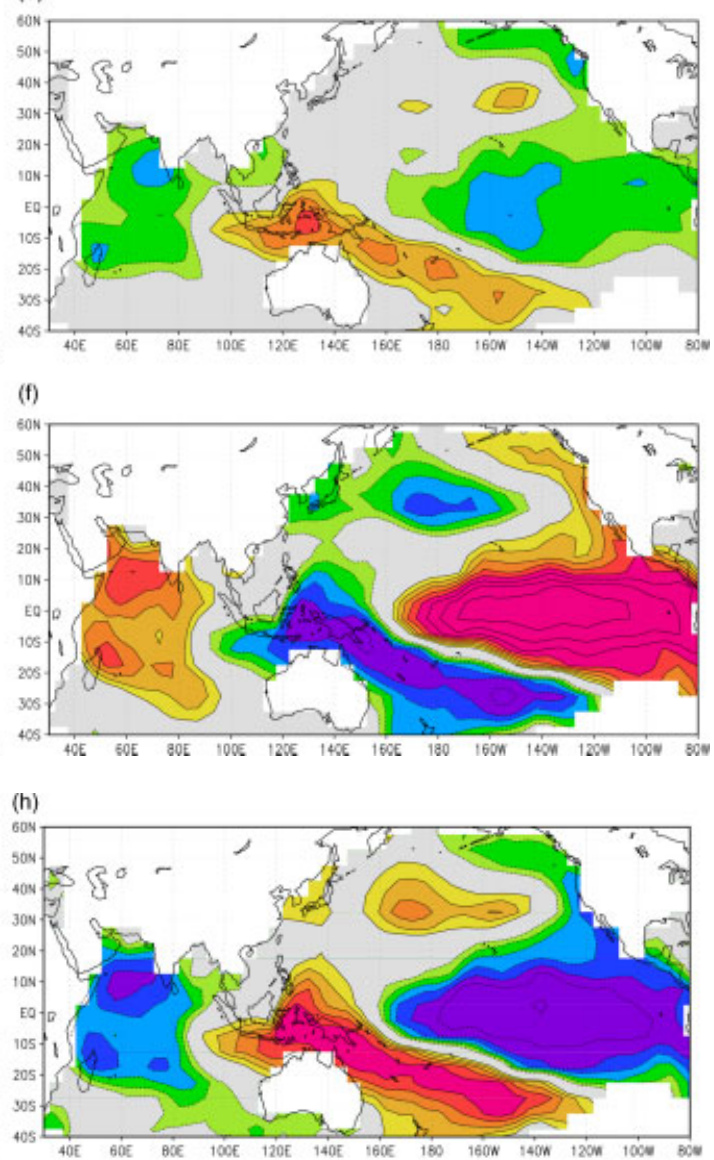

(j)

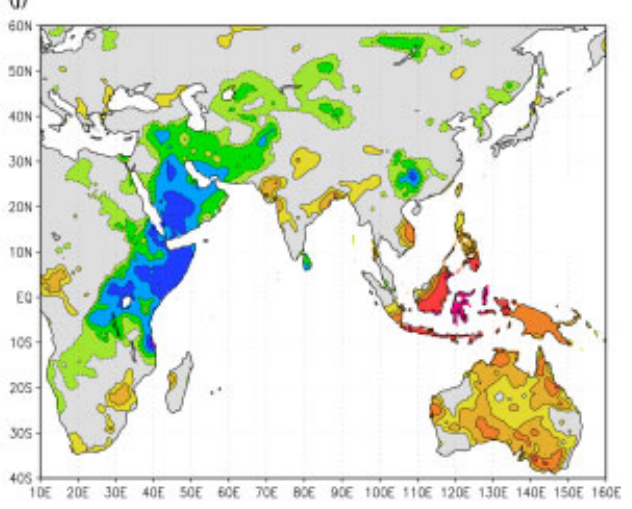

$\begin{array}{lllllllllll}-0.6 & -0.5 & -0.4 & -0.5 & -0.2 & 0.2 & 0.5 & 0.4 & 0.5 & 0.6\end{array}$

Figure 3. Spatial correlation fields computed for the recent period since 1958 (left panels) and since the late 19th century (right panels), comparing the Kaplan dipole index (a), (b), Java PDSI reconstruction (c), (d), Nino 3.4 SST (e), (f), and HADSLP2 SOI (Allan and Ansell, 2006; (g), (h)) with global SSTs from the Kaplan et al. (1998) dataset for the boreal fall (Sept-Oct). Note that all SST fields show dipole structure in the Indian Ocean as well as ENSO signatures in the Pacific Ocean. Figure 3(i)-(j) shows spatial correlations of the Java PDSI reconstruction with boreal fall precipitation data ((i): Sept-Oct and (j): Oct-Nov) for 1951-2000, illustrating the strong opposing relationship of rainfall between eastern Africa/Arabia versus Australasia, as well as linkages between Indian and Indonesian drought. This figure is available in colour online at www.interscience.wiley.com/ijoc 

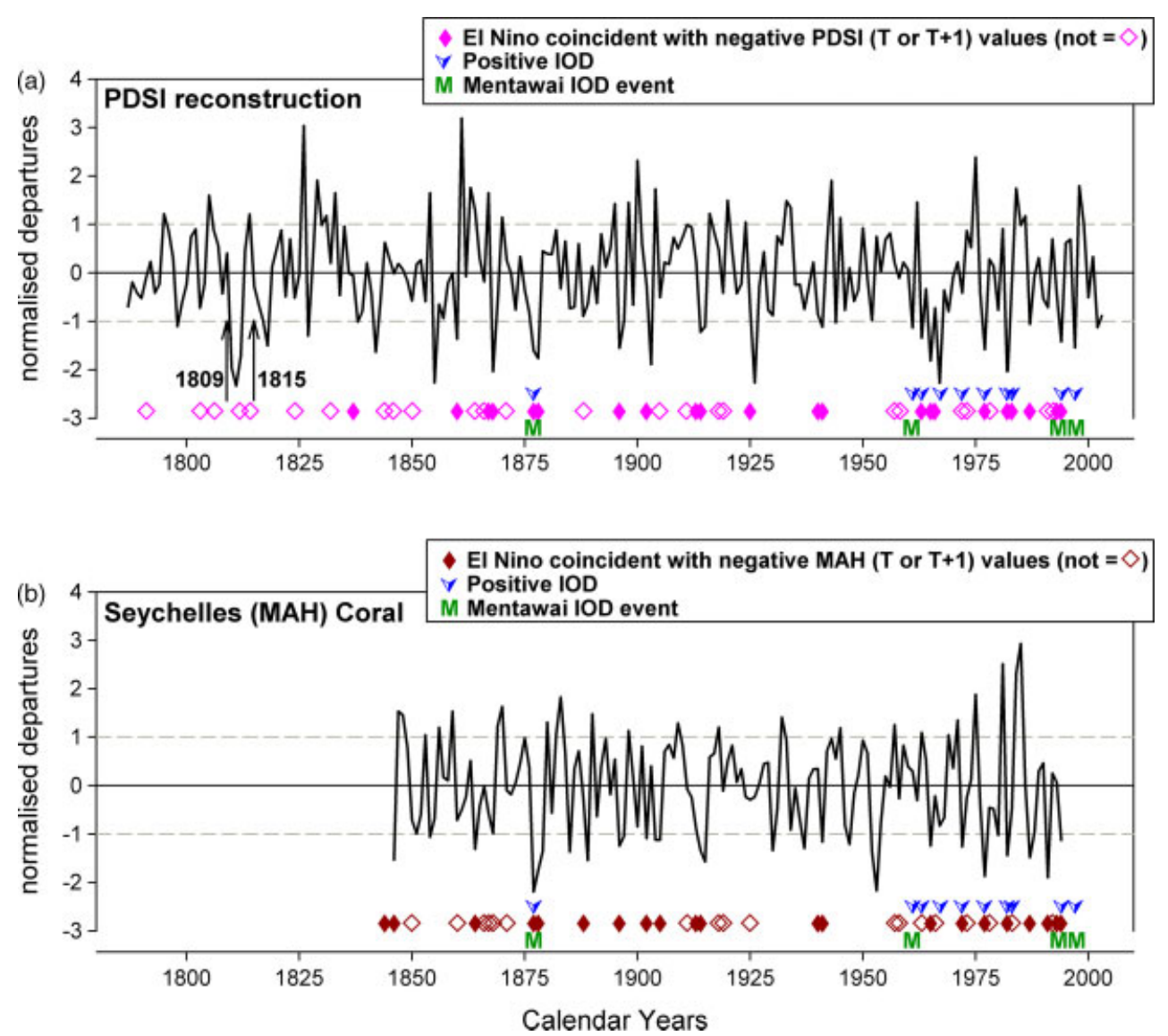

Figure 4. Analysis of extreme drought years in tropical Indian Ocean proxies. (a) In Java, PDSI reconstruction from 1787 to 2003. Positive (negative) PDSI values indicate wetter (drier) conditions. Horizontal dashed lines indicate $+/-1$ standard deviation from the mean. Pink diamonds denote El Niño warm events coincident with negative PDSI $(T$ or $T+1)$ values. Also labeled are positive IOD years from Saji and Yamagata (2003; blue arrows) and from the Abram et al. (2003) coral $\delta^{18} \mathrm{O}$ record for the Mentawai Islands, eastern Indian Ocean (labeled as green 'M's). PDSI drought events were previously linked to historical sea salt and rainfall measurements for Java (D'Arrigo et al., 2006a). El Niño anomalies are interpreted as being 'coincident' with the proxy data when the proxies show negative values in either the concurrent (year $t$ ) or following year $(t+1)$. Arrows at 1809 and 1815 indicate timing of two major volcanic eruptions (1809 unknown and 1815 Tambora events) that caused cold SSTs, and possibly, droughts for Indonesia and vicinity. (b) As for a, but using the detrended Seychelles coral $\delta^{18} \mathrm{O}$ record (Charles et al., 1997) for the boreal fall season showing low $\delta^{18} \mathrm{O}$ years and warmer SSTs inferred for positive IOD and El Niño events. Red diamonds denote El Niño warm events coincident with negative MAH $(T$ or $T+1)$ values. This figure is available in colour online at www.interscience.wiley.com/ijoc

identified in instrumental and historical data prior to the recent period, from 1787 to 1960 (Figure 4(a)). Low PDSI values from 1810 to 1812 may be partly a result of El Niños (Ortlieb, 2000), but may also reflect cold SSTs (and related drought) in the tropical Indo-Pacific following volcanic activity (Figure 4(a); Chenoweth, 2001; D'Arrigo et al., 2006a,b; Wilson et al., 2006). The magnitude of recent PDSI events does not appear to be particularly unique relative to previous events over the past two centuries.

Although the Java PDSI reconstruction indicates both Indian and Pacific Ocean SST extremes over the past two centuries, it is not sufficient by itself for generating a history of IOD events, since both positive IODs and El Niños result in the same signal (drought) over Java. Comparison of the PDSI reconstruction to other highresolution proxies provides additional information on past Indian Ocean and ENSO variability (Figure 4). For example, extreme isotopic values in the Mentawai coral record (Abram et al., 2003, Figure 4(a)) from the eastern pole of the IOD result from cool SSTs (and dry conditions) during major positive dipole events in 1877, 1961, 1994 and 1997. These IODs agree well with Java droughts: the normalized PDSI value is -1.4 averaged over these 4 years.

The Seychelles coral series is a logical candidate for representing the western arm of the IOD (Figures 1, 4(b); Charles et al., 1997). Correlation between the boreal fall Seychelles coral series and the Sep-Oct western Indian Ocean SST gridcell off Kenya used to identify the IOD is $r=-0.47$ (139 years); and $r=-0.44$ with the extended Kaplan Sept-Oct DMI (126 years). These results are consistent with the expectation that low $\delta^{18} \mathrm{O}$ values in the western Indian Ocean should be linked to warm SSTs (and wet conditions), positive IODs and El Niño-type conditions. The Seychelles record reveals good agreement with IOD and ENSO events in the recent period, and back in time when compared to the PDSI reconstruction as well as the listings of ENSO events. As for the Java reconstruction, however, there are some 
years that do not show the expected relationships: of the 29 negative values in the Seychelles record (related to warm SSTs), 20 (69\%; $p<0.0000)$ coincide with El Nino events. On the other hand, only $50 \%$ of the negative events coincide with positive IODs since 1960. As with the PDSI reconstruction, the coherence with La Nina and negative IOD events is relatively weak.

Both the Abram et al. (2003) and Charles et al. (1997) corals indicate extreme $\delta^{18} \mathrm{O}$ values around the time of the 1877 ENSO episode, which was coincident with a positive IOD. The 1877 event was one of the most widespread and intense episodes in the tropical IndoPacific in recent centuries. It shows the lowest $\delta^{18} \mathrm{O}$ value over the length of the original annual Seychelles record (Charles et al., 1997). It is also one of the most persistent autumn droughts in the Jakarta rain days record (values were consistently zero from Aug to Oct, second only to the 1961 event, when values were zero from July to Oct; Konnen et al. 1998). The 1877 event also coincides with a major DMI anomaly, drought in the Javan PDSI record, a very strong El Niño (Ortlieb, 2000; Allan et al., 2003), an IOD in the Mentawai coral data (not shown) and the second greatest Indian monsoon failure over the past millennium as documented in the Dasuopu, Tibet ice core record (Thompson et al., 2000; and see Grove, 1998) (Figure 5).

A composite analysis (Figure 6(a)) reveals that seven cases of Javan PDSI droughts over the common period with the monsoon record of Sontakke and Singh (1996; 1813-1995) show the expected relationship with a weakened Indian monsoon, typically associated with El Niños. However, four other major Java PDSI droughts actually coincide with a strengthened Indian monsoon (Sontakke and Singh, 1996). Three of these latter events have been identified as positive IODs [in 1877 (following the catastrophic 1877-1878 ENSO), 1961 and 1994]; the fourth, in 1842, may be another candidate. Figure 6(b) and (c) shows SST composites for the years of Java drought during strong and weak Indian monsoon seasons, with the strengthened Indian monsoon case having a more pronounced dipole pattern (Figure 6(b)). This result, although based on a limited number of cases, suggests an association between the Indian monsoon, Indian Ocean SSTs and Java drought that differs from the expected ENSO-Indian monsoon-Java drought relationship (see Discussion and Conclusions below).

We have performed several spectral analyses of the PDSI reconstruction to further investigate the expression of ENSO variability. MTM spectral analysis reveals spectral peaks at 2-3 and 5-6 years in the full reconstructed Javan PDSI (1787-2003), which fall within the classical ENSO bandwidth (Allan, 2000). Pronounced decadal-to-multidecadal variability is also noted in the reconstruction (Figure 7(a); D'Arrigo et al., 2006a). Morlet wavelet analysis (Figure 7(b); Grinsted et al., 2004) indicates that the strength of variability in the PDSI series at the ENSO and decadal-to-multidecadal bands has varied in time, with a period of quiescence occurring during the middle part of the 20th century. Furthermore, the coherence between the PDSI reconstruction and Niño3-4 SSTs has varied in time across most spectral bands (Figure 7(c), Grinsted et al., 2004). The periods of greatest coherency, however, occur on interannual timescales spanning the classical ENSO bandwidth. Additionally, normalized, scale-average time series (not shown) between the 2-8 year bands in the PDSI reconstruction and Niño3-4 SSTs are significantly correlated with each other $(r=0.273, p=0.0018)$.

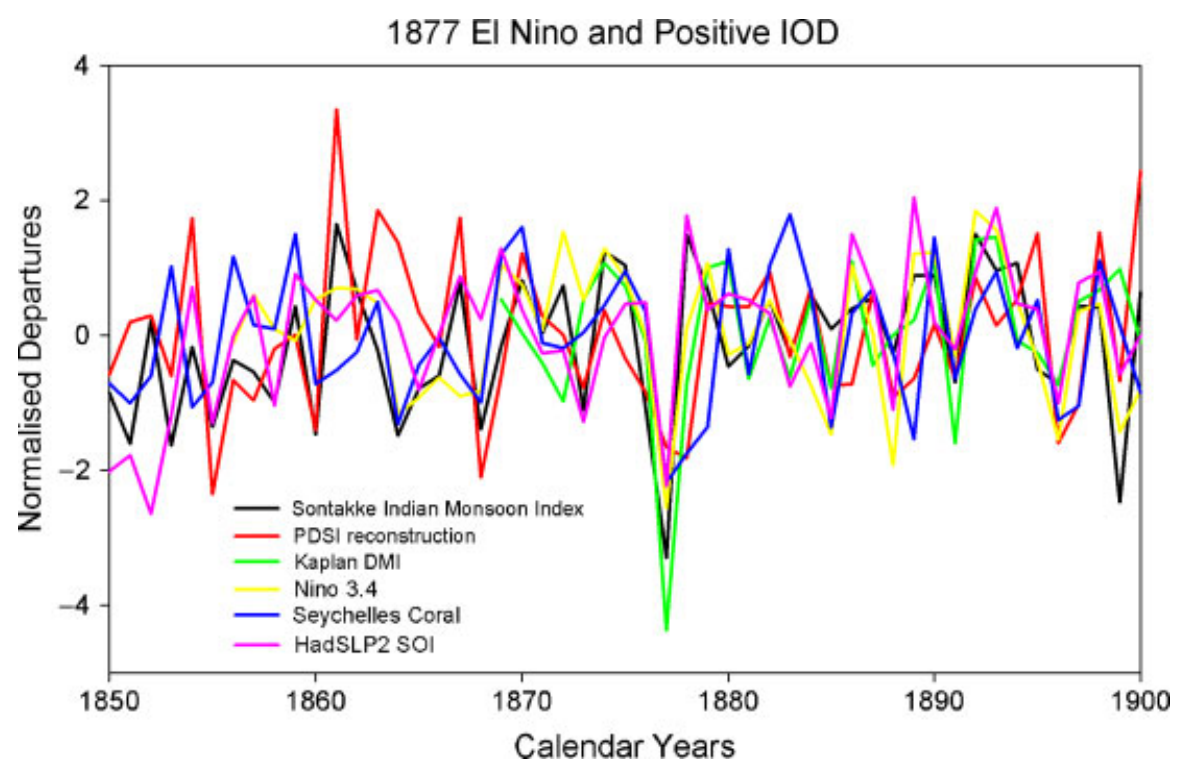

Figure 5. Time series of the catastrophic combined 1877 El Niño and positive IOD episode. Plot of normalized instrumental and proxy time series for 1850-1900 time period, emphasizing the 1877 event. Time series include the Sept-Oct Kaplan DMI (inverted) (Kaplan et al., 1998), Nino 3.4 SSTs (http://www.cpc.noaa.gov), Seychelles coral $\delta^{18} \mathrm{O}$ (Charles et al., 1997), Indian monsoon index (Sontakke et al., 1993; Sontakke and Singh, 1996), HADSLP2 SOI and PDSI reconstruction (D'Arrigo et al., 2006a). This event is also present in the Mentawai corals (see Figure 4(a)). This figure is available in colour online at www.interscience.wiley.com/ijoc 
(a)

(a) PDSI Droughts: Strong and Weak Monsoons

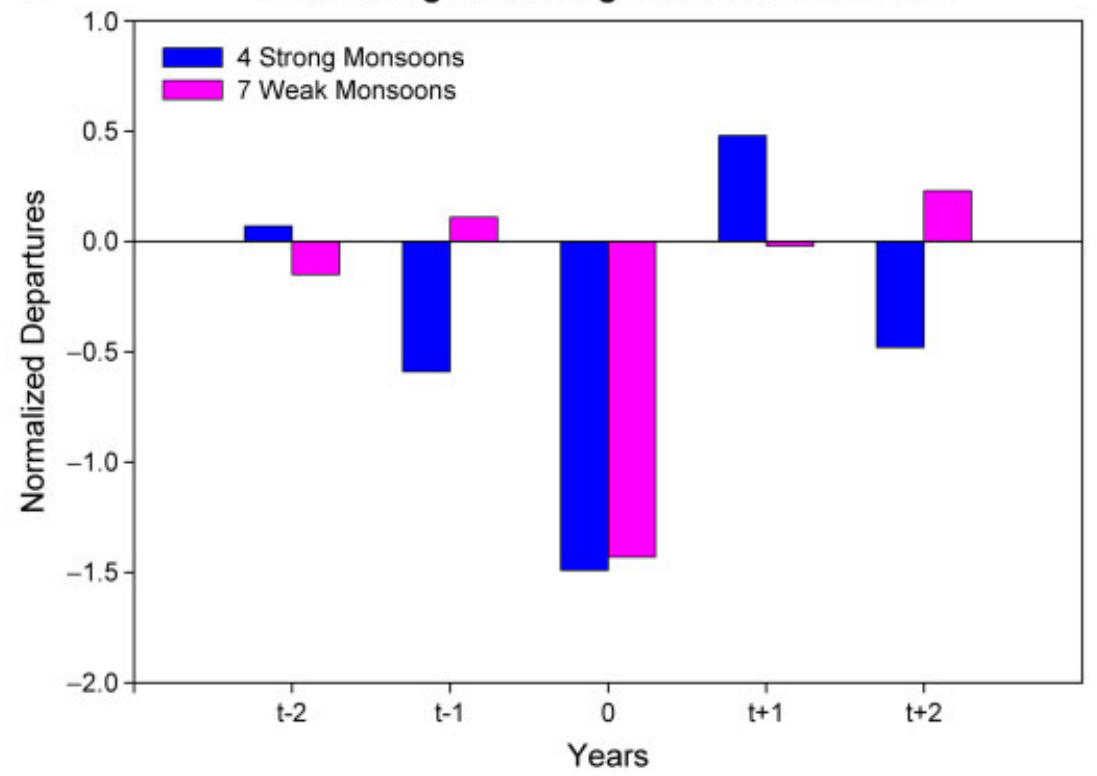

(b)

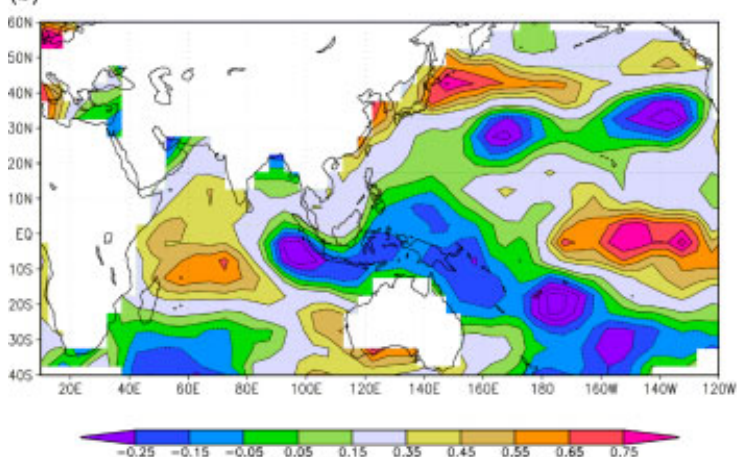

(c)

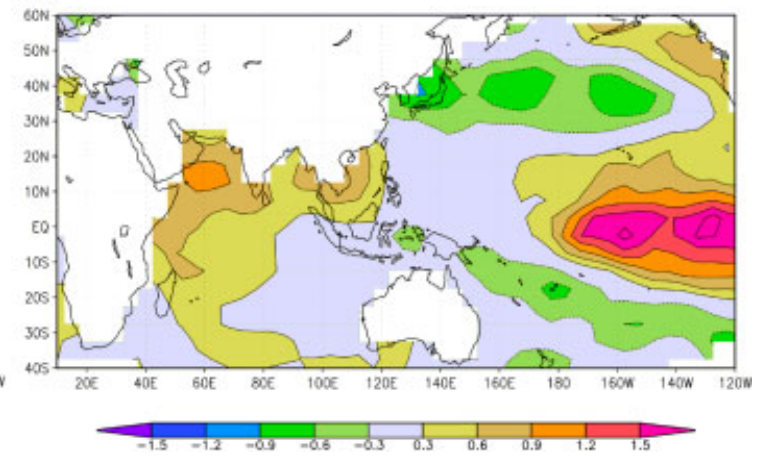

Figure 6. Analyses of reconstructed PDSI droughts linked to strong and weak Indian monsoons. (a) Composited average of normalized Java PDSI reconstructed drought departures during overlapping years (1813-1995) of strong (blue: 1842, 1878, 1961, 1994) and weak (pink: 1855, 1860, 1868, 1877, 1941, 1965, 1987) Indian monsoons (Sontakke and Singh, 1996). PDSI drought and weak monsoon years defined as those with values below 1 negative standard deviation; strong monsoons defined as those years with normalized values above 1 standard deviation. Weak (strong) monsoon years linked to Java drought generally associated with El Niño-like (dipole-like) conditions in year 0 (current year). Averaged normalized departures also shown for two years prior and two years following these reconstructed Java drought events. Lower panels indicate Kaplan Sep-Oct SST composites for the two categories of Java drought (for events since 1856): (b) during strong Indian monsoons and (c) during weak monsoons. The former shows a stronger dipole-type signal in the Indian Ocean. This figure is available in colour online at www.interscience.wiley.com/ijoc

\section{Discussion and conclusions}

We have used a multiproxy reconstruction of the PDSI drought index to demonstrate that rainfall over Java and Indonesia is impacted by both tropical Indian Ocean and Pacific Ocean SSTs over the past two centuries. Reconstructed drought years over Java were found to agree reasonably well with both ENSO and IOD episodes identified in instrumental and documentary data, particularly after $\sim 1850$. The PDSI reconstruction is thus one useful indicator of Indian Ocean-related SST and rainfall extremes for the eastern pole of the IOD adjacent to Java/Sumatra. Before recent decades, major drought events in Java can largely be accounted for by known El Niño episodes. This finding, along with the documentation of IODs indicated for the Mentawai corals (Abram et al., 2003, 2007) and the apparent hiatus of major IODs in the extended DMI from 1878 to 1960 , suggests that
IOD activity was relatively infrequent over the past two centuries, prior to recent decades. Indian Ocean coral data from the two poles of the IOD (Charles et al., 1997; Abram et al., 2003) reveal reasonably good agreement with the PDSI reconstruction. In future investigations, transects of these and other coral and tree-ring records (e.g. Moore, 1995; Cole et al., 2000; Abram et al., 2003; Pfeiffer et al., 2004; Zinke et al., 2004; Therrell et al., 2006) could be used to develop a more detailed, continuous spatial history of tropical Indian and Pacific Ocean climate and its relation to ENSO and the Asian monsoon.

While we have shown that the Javan PDSI record is reflective of tropical Indian Ocean SST variability, we do not mean to imply that IODs are necessarily distinct from the ENSO system. In fact, evidence in this paper suggests that the opposite is true. One consideration is that the PDSI reconstruction demonstrates statistically significant 

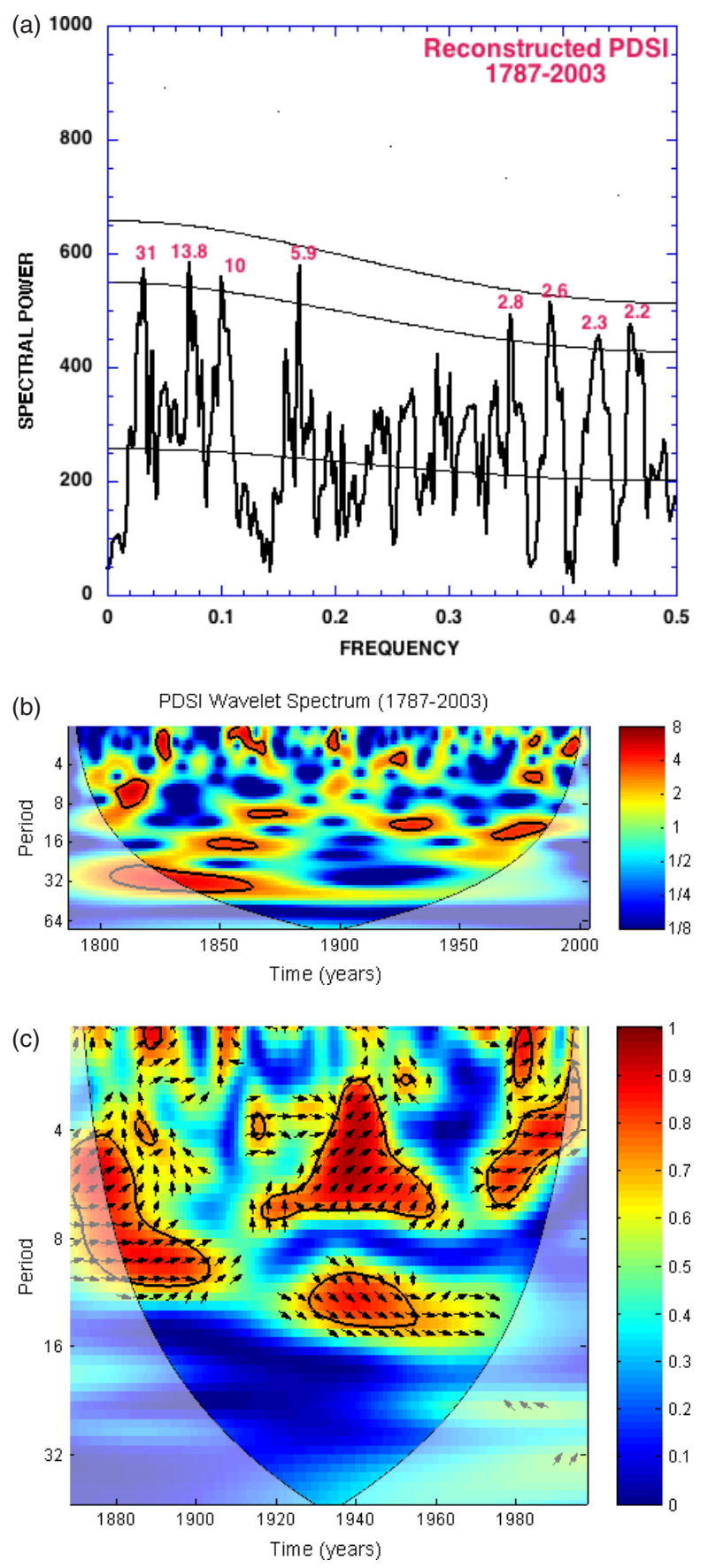

Figure 7. Spectral analyses of Java PDSI reconstruction. (a) MTM analysis (Mann and Lees, 1996) of full Java PDSI reconstruction from 1787 to 2003 (instrumental data spliced onto reconstruction for 1989-2003 period). Thin solid lines in MTM plot indicate significance at 50, 90 and $95 \%$ levels. (b) The continuous wavelet power spectrum for the PDSI reconstruction from 1787 to 2003. Black contours bind regions that are significant against a red noise null hypothesis. Lighter shaded regions indicate the cone of influence where edge effects are likely and the results should not be interpreted. (c) Squared wavelet coherence between the PDSI reconstruction and Niño-3.4 SST. Arrows indicate the phase of the coherence, where right is in phase and left is antiphase; note that significant regions all show an in-phase relationship, which supports the idea that there may be a simple cause and effect relationship between the two phenomena. Otherwise as in (b). Note decadal-to-multidecadal variability in both the MTM and wavelet analyses (interpreted as being indicative of protracted and low-frequency ENSO variability), in addition to spectral activity in more classical ENSO bandwidth of 2-7 years. This figure is available in colour online at www.interscience.wiley.com/ijoc correlations with ENSO on interannual to decadal time scales, as has been found for the Indian Ocean coral proxies (Charles et al., 1997; Cole et al., 2000). Like these coral series, the Java PDSI indicates spectral activity at $\sim 5-6$ and $10-14$ years (Figure 7). Such annual to decadal (as well as multidecadal) variability in the Javan PDSI appears to be best explained by ENSO (as was found for the Malindi coral by Cole et al., 2000) rather than specifically by dipole (Saji et al., 1999) or Asian monsoon (Charles et al., 1997) related effects. Our observations thus lend support to the concept that Indian Ocean SST activity related to IODs results from the interaction of quasi-biennial, 'classical' ENSO and decadal-scale ENSO-like modes of variability and their expression across the Indian Ocean basin (Allan and D'Arrigo, 1999; Allan, 2000; Allan et al., 2001, 2003).

The coincidence of some major Javan droughts with a strengthened monsoon over India suggests a monsoon-Indian Ocean climate (including SSTs and winds) relationship, although this observation is based on limited data. In a related study, Ihara et al. (2007; and see Gadgil et al., 2004) found that the state of the Indian Ocean modulates the ENSO-monsoon relationship, with a negative EQWIN increasing the likelihood of a stronger Indian monsoon despite the presence of El Niño. Although not well understood, it appears that in such cases a negative EQWIN state may weaken the impact of ENSO on the Indian monsoon by inducing anomalous surface divergence in the eastern tropical Indian Ocean, subsequently stimulating convection that propagates northward causing anomalous ascent and surplus rainfall over India. A stronger monsoon can, in turn, generate easterly wind anomalies that cool the eastern Indian Ocean, stimulating upwelling of cool deep waters and positive dipole conditions, with decreased convergence of moist air and ensuing drought in Java/Sumatra (Gadgil et al., 2004; Ihara et al., 2007). These two studies also found that a better model of Indian monsoon rainfall could be obtained using both the EQWIN index and Niño-3 SSTs as predictors, rather than either index alone (Gadgil et al., 2004; Ihara et al., 2007). It is also worth noting that other phenomena may potentially contribute to irregularities in expected ENSO patterns and teleconnections (such as the Madden-Julian Oscillation, or MJO, Zhang et al., 2001).

Here we have shown that stronger Indian monsoons can also be linked to drought (a failed Indonesian monsoon) in Java during positive IOD-type conditions over the past two centuries. Similar to the results of Gadgil et al. (2004) and Ihara et al. (2007) noted above, analysis reveals that a better regression model of the Java PDSI reconstruction can be obtained using both Niño-3.4 SSTs and the EQWIN index than either index alone, with over $54 \%$ of the variance accounted for in the PDSI estimates (see D'Arrigo et al. in press, IJ Clim for a more detailed analysis). The strong correlation between the Java PDSI reconstruction and EQWIN, and possible links to the Indian monsoon, are intriguing, and will be investigated in more detail in a future study. Improved spatial coverage of proxy data, modeling and 
other analyses will further aid our understanding of the nature and origin of Indian Ocean climatic variability, its relation to ENSO and the Asian monsoon, and how such activity may be modulated by future greenhouse warming.

\section{Acknowledgements}

This study was funded by the National Science Foundation's Earth System History and Paleoclimate programs (Grant No. OCE-04-02474). Rob Wilson is funded by the European Community under research contract 017008-2 MILLENNIUM. Rob Allan was supported by the UK Department for Environment, Food and Rural Affairs (DEFRA), Climate Prediction Program, and this paper is UK Crown Copyright. We also gratefully acknowledge the Indonesian Institute of Sciences (LIPI). We thank N. Abram, C. Charles and M. Moore for data and assistance, D. Parker for reviewing an early version of the manuscript and A. Wilson for help with the probability analysis. Crosswavelet and wavelet coherence software were provided by A. Grinsted. Lamont-Doherty Earth Observatory Contribution No. 7130.

\section{References}

Abram N, Gagan M, McCulloch M, Chappell J, Hantoro W. 2003. Coral reef death during the 1997 Indian Ocean dipole linked to Indonesian wildfires. Science 301: 952-955.

Abram N, Gagan M, Liu Z, Hantoro W, McCulloch M, Suwargadi B. 2007. Seasonal characteristics of the Indian Ocean dipole during the Holocene epoch. Nature 445: 299-302.

Abram N, Gagan M, Liu Z, Hantoro W, McCulloch M, Suwargadi B, Chappell J. 2005. Recent evolution of tropical climate variability in the Indian Ocean region. Geophysical Research and Abstracts 7: 049302 .

Aldrian E, Susanto D. 2003. Identification of three dominant rainfall regions within Indonesia and their relationship to sea surface temperature. International Journal of Climatology 23: 1435-1452.

Allan RJ. 2000. ENSO and climatic variability in the past 150 years. In ENSO: Multiscale Variability and Global and Regional Impacts, Diaz HF, Markgraf V (eds). Cambridge University Press: Cambridge; 3-55.

Allan R, D'Arrigo R. 1999. 'Persistent' ENSO sequences: how unusual was the 1990-1995 El Niño? The Holocene 9: 101-118.

Allan R, Ansell T. 2006. A new globally-complete monthly historical gridded sea-level pressure data set (HadSLP2): 1850-2004. Journal of Climate 19: 5816-5812.

Allan R, Reason C, Lindesay J, Ansell T. 2003. 'Protracted' ENSO episodes and their impacts in the Indian Ocean region. Deep-Sea Research II 50: 2331-2347.

Allan R, Chambers D, Drosdwosky W, Hendon H, Latif M, Nicholls N, Smith I, Stone R, Tourre Y. 2001. Is there an Indian Ocean dipole, and is it independent of the El Niño-Southern Oscillation? Climate Variability and Predictability Exchanges 6: 18-22.

Baquero-Bernal A, Latif M, Legutke S. 2002. On dipole-like variability in the tropical Indian Ocean. Journal of Climate 15: 1358-1368.

Beck C, Grieser J, Rudolf B. 2005. A new monthly precipitation climatology for the global land areas for the period 1951 to 2000. Climate Status Report 2004. German Weather Service: Offenbach, Germany; 181-190.

Behera S, Luo L, Masson S, Rao S, Sakuma H. 2006. A CGCM study on the interaction between IOD and ENSO. Journal of Climate 19: $1688-1705$

Chakraborty S. 2006. Coral records from the northern Indian ocean: understanding monsoon variability. Journal of the Geological Society India 68: 395-405.

Charles C, Hunter D, Fairbanks R. 1997. Interaction between the ENSO and the Asian monsoon in a coral record of tropical climate. Science 277: 925-928.
Charles CD, Cobb K, Moore MD, Fairbanks RG. 2003. Monsoontropical ocean interaction in a network of coral records spanning the 20th century. Marine Geology 201: 207-222.

Chenoweth M. 2001. Two major volcanic cooling episodes derived from global marine air temperature, AD 1807-1827. Geophysical Research Letters 28: 2963-2966.

Cole J, Dunbar R, McClanahan T, Muthiga N. 2000. Tropical Pacific forcing of decadal SST variability in the western Indian Ocean over the past two centuries. Science 287: 617-619.

Dai A, Trenberth K, Qian T. 2004. A global data set of Palmer Drought Severity Index for 1870-2002: relationship with soil moisture and effects of surface warming. Journal of Hydrometeorology 5: 1117-1130.

D’Arrigo R, Wilson R, Palmer J, Krusic P, Curtis A, Sakulich J, Bijaksana S, Zulaikah S, Ngkoimani O. 2006a. Monsoon drought over Java, Indonesia during the past two centuries. Geophysical Research Letters 33: L04709, DOI:10.1029/2005GL025465.

D'Arrigo R, Wilson R, Palmer J, Krusic P, Curtis A, Sakulich J, Bijaksana S, Zulaikah S, Ngkoimani O, Tudhope S. 2006b. Reconstructed Indonesian warm pool SSTs from tree rings and corals: linkages with ENSO and the Asian monsoon. Paleoceanography 21: PA3005, DOI:10.1029/2005PA001256.

D'Arrigo R, Wilson R. El Nino and Indian Ocean influences on Indonesian drought:implications for forecasting rainfall and crop productivity. International Journal of Climatology (in press).

Dommenget D, Latif M. 2002. A cautionary note on the interpretation of EOFs. Journal of Climate 15: 216-225.

Fischer A, Terray P, Guilyardi E, Gualdi S, Delacluse P. 2005. Two independent triggers for the Indian Ocean Dipole/Zonal Mode in a coupled GCM. Journal of Climate 18: 3428-3449.

Fritts H. 1976. Tree Rings and Climate. Academic Press: New York.

Gadgil S, Vinayachandran P, Francis P, Siddhartha G. 2004. Extremes of the Indian summer monsoon rainfall, ENSO and equatorial Indian Ocean oscillation. Geophysical Research Letters 31: L12213.

Grinsted A, Moore J, Jevrejeva S. 2004. Application of the cross wavelet transform and wavelet coherence to geophysical time series. Nonlinear Processes in Geophysics 11: 561-566.

Grove R. 1998. Global impact of the 1789-1793 El Niño. Nature 393: 318-319.

Ihara C, Kushnir Y, Cane M. Warming trend of the Indian Ocean SST and Indian Ocean Dipole from 1880 to 2004. Journal of Climate In press.

Ihara C, Kushnir Y, Cane M, De La Pena V. 2007. Indian summer monsoon rainfall and its links with ENSO and Indian Ocean climate anomalies. International Journal of Climatology 27: 179-187.

Kaplan A, Cane M, Kushnir Y, Clement A, Blumenthal M, Rajagopalan B. 1998. Analyses of global sea surface temperature 1856-1991. Journal of Geophysical Research-Oceans 103: 18567-18589.

Kayanne H, Iijima H, Nakamura N, McClanahan T, Behera S, Yamagata T. 2006. Indian Ocean dipole index recorded in Kenyan coral annual density bands. Geophysical Research Letters 33: L19709, DOI:10.1029/2006GL027168.

Konnen G, Jones P, Kaltofen M, Allan R. 1998. Pre-1866 extensions of the Southern Oscillation index using early Indonesian and Tahitian meteorological readings. Journal of Climate 11: 2325-2339.

Kumar K, Rajagopalan B, Hoerling M, Bates G, Cane M. 2006. Unraveling the mystery of Indian monsoon failure During El Niño. Science 314: 115-119.

Mann ME, Lees J. 1996. Robust estimation of background noise and signal detection in climatic time series. Climatic Change 33: 409-445.

Meyers G, McIntosh P, Pigot L, Pook M. 2007. The years of El Niño, La Niña and interactions with the tropical Indian Ocean. Journal of Climate 20: 2872-2880.

Moore M. 1995. Proxy records of the Indonesian Low and the El NiñoSouthern Oscillation (ENSO) from stable isotope measurements of Indonesian reef corals. Ph.D. thesis, University of California at Berkeley.

Ortlieb L. 2000. The documented historical record of El Niño events in Peru: an update of the Quinn record (sixteenth through nineteenth centuries). In El Niño and the Southern Oscillation: Multiscale Variability and Global and Regional Impacts, Diaz H, Markgraf V (eds). Cambridge University Press: Cambridge; 207-295.

O'Sullivan D. 1994. El Nino and the Southern Oscillation, http://www.longpaddock.qld.gov.au/Help/ElNinoSouthern Oscillation/. 
List taken from: Mean Sea Level Pressure Indices of the El NiñoSouthern Oscillation: relevance to stream discharge in southeastern Australia, April 1996. By Allan RJ, Beard GS, Close A, Herczeg AL, Jones PD, Simpson HJ. CSIRO Divisional Report 96/1 ISSN 10335579.

Pfeiffer M, Dullo W. 2006. Monsoon-induced cooling of the western equatorial Indian Ocean as recorded in coral oxygen isotope records from the Seychelles covering the period of 1840-1994 AD. Quaternary Science Reviews 25: 993-1009.

Pfeiffer M, Dullo W, Eisenhauer A. 2004. Variability of the intertropical convergence Zone recorded in coral isotopic records from the central Indian Ocean (Chagos Archipelago). Quaternary Research 61: 245-255.

Rayner N, Brohan P, Parker D, Folland C, Kennedy J, Vanicek M, Ansell T, Tett S. 2006. Improved analyses of changes and uncertainties in sea surface temperature measured in situ since the mid-nineteenth century: the HADSST2 data set. Journal of Climate 19: $446-469$

Reason CJC, Allan RJ, Lindesay JA, Ansell TJ. 2000. ENSO and climatic signals across the Indian Ocean basin in the global context: Part I, interannual composite patterns. International Journal of Climatology 20: 1285-1327.

Saji N, Yamagata T. 2003. Possible impacts of Indian Ocean Dipole mode events on global climate. Climatic Research 25: 151-169.

Saji N, Goswami B, Vinayachandran P, Yamagata T. 1999. A dipole mode in the tropical Indian Ocean. Nature 401: 360-363.

Sontakke N, Singh N. 1996. Longest instrumental and regional AllIndia summer monsoon rainfall series using optimum observations: reconstruction and update. The Holocene 6: 315-331.

Sontakke N, Pant G, Singh N. 1993. Construction of all-India summe monsoon rainfall series for the period 1844-1991. Journal of Climate 6: $1807-1811$.

Therrell M, Stahle D, Ries L, Shugart H. 2006. Tree-ring reconstructed rainfall variability in Zimbabwe. Climate Dynamics 26: 677-685.
Thompson L, Yao T, Mosley-Thompson E, Davis M, Henderson K, Lin P. 2000. A high-resolution millennial record of the South Asian monsoon from Himalayan ice cores. Science 289: 1916-1919.

Torrence C, Compo G. 1998. A practical guide to wavelet analysis. Bulletin of the American Meteorological Society 79: 61-78.

Trenberth K, Stepaniak D. 2001. Indices of El Niño evolution. Journal of Climate 14: 1697-1701.

Webster P, Moore A, Ioschnigg J, Leben R. 1999. Coupled oceanatmosphere dynamics in the Indian Ocean during 1997-1998. Nature 401: $356-360$.

Whetton P, Rutherford I. 1994. El Niño-Southern Oscillation teleconnections in the Eastern hemisphere over the last 500 years. Climate Change 28: 221-253.

Wilson R, Tudhope A, Brohan P, Briffa K, Osborn T, Tett S. 2006. Two hundred-fifty years of reconstructed and modeled tropical temperatures. Journal of Geophysical Research 111: C10007, DOI: $10.1029 / 2005 J C 003188$.

Worley S, Woodruff S, Reynolds R, Lubker S, Lott N. 2005. ICOADS release 2.1 data and products. International Journal of Climatology 25: $823-842$

Wright PB, Mitchell TP, Wallace JM. 1985. Relationships Between Surface Observations over the Global Oceans and the Southern Oscillation. Data Report ERL PMEL-12, Seattle, NOAA.

Zhang C, Hendon H, Kessler W, Rosati A. 2001. A workshop on the MJO and ENSO. Bulletin of the American Meteorological Society 82: $971-976$

Zinke J, Dullo W, Heiss G, Eisenhauer A. 2004. ENSO and Indian Ocean subtropical dipole variability is recorded in a coral record off southwest Madagascar for the period 1659 to 1995. Earth Planetary Science Letters 228: 177-194.

Zinke J, Pfeiffer M, Timm O, Dullo W, Davies G. 2005. Atmosphereocean dynamics in the western Indian Ocean recorded in corals. Philosophical Transactions of the Royal Society A 363: 121-142. 